\title{
Martian flotilla prepares
}

\section{Washington}

WITH a huge amount of luck, and an equal amount of hard work, 1992 will see an international fleet of tiny spacecraft, each with gigantic sails of aluminized plastic, set off on a sailing race across space. The winner will be the first to ride to Mars on the wind of photons from the Sun.

The race should take two to three years, according to Klaus P. Heiss, chairman of the group is organizing the race as one of the Christopher Columbus Quincentenary Jubilee Commission's official events. Over half the voyage time is needed to gain speed to break out of the high Earth orbit from which the craft will be launched. Then it's a year of plain sailing to Mars.

There were to have been three craft, representing America, Europe and Asia and named Nina, Pinta and Santa Maria after Columbus's ships, and the three winning designs should have been selected last year. But the schedule is behind and the number of good designs large. Britain, the Soviet Union, China and Italy have all submitted proposals, as have three US teams and a Canadian team. An Israeli group is expected to join in.

Heiss now talks optimistically of more than three craft going into space, and team representatives from Canada, Johns Hopkins University, Massachusetts Institute of Technology (MIT), Britain and Italy all say they can probably find ways to raise the $\$ 5-10$ million needed to build their sail craft. But getting the craft into space in another matter. A single launch into Earth orbit could cost $\$ 10_{-}$ 100 million, and all contenders are looking to Heiss to raise the money.

Heiss says he has one "US launch commitment to geosynchronous orbit", but he cannot yet reveal the identity of the backer. He also says that the Italians will be able to launch their craft on an Ariane rocket, but a representative of the Italian team at the aerospace manufacturer Aeritalia could not confirm Heiss's statement. He did say, however, that an announcement about the race can be expected next week at a space commerce congress in Montreux, Switzerland.
All the sail craft designs owe something to the past. The idea has come up often in science fiction novels (Arthur C. Clarke's The Wind from the Sun was a classic of the genre), and the National Aeronautics and Space Administration (NASA) paid for a design study in the $1960 \mathrm{~s}$. Plans were made in the 1970 s to sail out to meet Halley's comet.

The race craft have to be light and be able to deploy large sails (up to $10,000 \mathrm{~m}^{2}$ ) from a tiny volume. Most of them end up looking like umbrellas or multi-rayed sunflowers - carried to an extreme in the Johns Hopkins University design that has 480 'petals' which unroll during deployment. The British craft, designed by a team at Cambridge Consultants, looks more like a gigantic flying chapati or pizza, though its designers describe it as a "space manta ray". The sails tow tiny craft equipped with sensors, communication gear and steering lines. The designs differ most in how the sails are unfurled and kept extended.

The Canadian Space Society's craft is a little different, being a cross between an umbrella and a venetian blind. Its hexagonal sail is divided into thin strips and the craft can be steered by changing their pitch angle.

The "gadfly" in the fleet, as Heiss refers to it, is the radical design from Andreas von Flotow at MIT. His "helio-gyro" weighs a mere $20 \mathrm{~kg}$, less than a tenth the weight of most of the others, and looks like a windmill with eight long arms radiating from a central core. Each of the arms is made from plastic film and can simply be rolled up for compact storage during launch. Once in space, the craft will be spun on its axis by a small rocket so that centrifugal force unwinds the arms and keep them rigid.

Small changes in the pitch of the blades will alter the direction in which it is blown. The craft is incredibly simple - mechanical devices (which are often unreliable) are not needed to deploy the arms and such tiny forces are need to control their pitch that motors can be replaced by pizoelectic films.

Alun Anderson

\section{IMAGE UNAVAILABLE FOR COPYRIGHT REASONS}

TWENTY-FIVE YEARS OF OBSCURITY: The US Air Force's still-secret SR-71 Blackbird spy-plane 'retired' in a blaze of glory last week, breaking speed and distance records by flying for 2,300 miles $(3,680 \mathrm{~km})$ between Los Angeles and Washington in 64 minutes 5 seconds. The aircraft holds the absolute air speed record at 2,193 m.p.h. (over a measured course) and altitude record of 85,069 feet (AP).
IMPORT REGULATIONS

\section{Brazil cuts red tape}

\section{Sâo Paulo}

BARELY a week before a new federal government was due to assume power, the Brazilian Ministry of Science and Technology (MCT) finally gave in to more than 15 years of appeals from scientists and agreed to reduce restrictions on the import of scientific equipment and lab materials.

The new legislation is an enormous improvement, according to Fernando Galembeck, secretary-general of the Brazilian Society for the Progress of Science (SBPC), but there remain problems with its form. The government has issued only a medida provisoria (provisional measure), which does not have the same status as a law passed through Congress and will cease to have effect unless it is reissued or turned into a normal law. That will be the responsibility of the new government of president Fernando Collor de Mello, who assumes power this week.

Collor is sure to back a new law, according to Antonio Paes de Carvalho, secretarygeneral of the Bio-Rio foundation. Paes de Carvalho is an advisor to Collor and may be chosen to head the new Secretariat of Science and Technology.

Scientists have had enormous difficulties in importing materials as an import worth a few hundred dollars faced the same set of delays, taxes and labrynthine regulations as multi-million dollar imports by giant corporations. The new measure exempts scientists from import taxes and concentrates responsibility in the MCT's National Council for Scientific and Technological Development (CNPq).

A quota for imports will be set each year by the Ministry of Finance and CNPq. The Minister of Science and Technology, Decio Leal de Zagottis, says that the quota amounts to US\$80 million per year.

Ricardo Bonalume

NUCLEAR FUELS -

\section{Allegations of laxity \\ Bangalore}

IN response to growing numbers of reports of birth deformities, leukaemia and bone diseases among people living in the vicinity of the India's Nuclear Fuels Complex (NFC), on the outskirts of Hyderabad, company officials are maintaining that radiation exposure in the plant has never exceeded permissible limits. But a study by a team from the Bhabha Atomic Research Centre has shown that nitrate and fluoride levels in wells near the NFC are much higher than the safe levels given by the World Health Organization for drinking water. Members of Community Against Pollution, a local environmental group, claim that NFC, which makes nuclear fuel bundles and core sub-assemblies, ignores safety regulations and keeps inadequate records of the workers' exposure to radiation and chemicals.

Radhakrishna Rao 